\title{
Study of the limits of resistance of endophytic fungi Fusarium equiseti and Cylindrocarpon magnusianum to the action of copper and chromium (VI)
}

\author{
Nadezhda Islamova*, Irina Bukharina, and Anastasiya Isupova \\ Udmurt State University, Universitetskaya st., 1, 426034 Izhevsk, Russia
}

\begin{abstract}
Endophytic fungi are promising subjects for study as agents for increasing plant resistance. They have a wide distribution area, diverse morphology and are able to adapt to stressful environmental conditions. We have carried out studies on the effect of different concentrations of copper and chromium on the growth of endophytic fungi Fusarium equiseti and Cylindrocarpon magnusianum. The results showed that these micromycetes are able to adapt to a high content of heavy metals in the environment and, therefore, can be used in the development of technologies for increasing plant resistance.
\end{abstract}

\section{Introduction}

Recently, great interest of the scientific community is directed to the study of consortium relations of higher plants with endophytic microorganisms, including micromycetes. Microscopic fungi inhabiting plant roots increase the efficiency of the assimilation of mineral elements by plants $[1,5]$. Besides, root endophytic fungi help plants to adapt and show resistance to environmental stress factors: high temperature, drought, soils salinization, including heavy metals (HM), and action of pathogenic organisms $[3,6,7]$.

However, a difficult moment in the study and practical application of the most studied in this area arbuscular-mycorrhizal fungi that form endomycorrhiza is their obligate symbiotrophism and, as a consequence, the complexity of their cultivation in the mycorrhization technology development. In this regard, endophytic micromycetes are of greater interest for study [8]. Endophytic fungi have a wide distribution area, they are morphologically diverse in nature and are able to adapt to stressful environmental conditions [9]. Moreover, fungal cultures isolated from contaminated soils have wider tolerance limits to the action of pollutants, including salts of heavy metals $[10,11,9]$.

Fusarium equiseti and Cylindrocarpon magnusianum are representatives of root endophytes, which are widely found in nature [13]. Fusarium equiseti was previously considered a pathogen $[14,15]$, however, in recent years in research, the fungus has shown the ability to fight root pathogens [13]. Cylindrocarpon magnusianum is found in places of soil pollution with oil, which can be in demand in the restoration of oil-contaminated lands

*Corresponding author: islamovanadezhda@mail.ru 
[16]. In addition, in our earlier studies, both fungi showed high resistance to the content of sodium chloride in the substrate [2]. Based on this, we set a goal to study the resistance limits of Fusarium equiseti and Cylindrocarpon magnusianum to different concentrations of heavy metal salts, in particular, copper and chromium, and evaluate the possibility of using them to develop a technology for increasing plant resistance to HM salts.

\section{Methods}

Fusarium equiseti and Cylindrocarpon magnusianum cultures, which were used in our studies, were isolated from the root system of plants growing in contaminated soils in the city of Izhevsk (Udmurt Republic). The mushrooms were cultivated on an agar medium with the addition of different concentrations of copper and chromium salts (biogenic and non-biogenic chemical elements): $\mathrm{Cu}-50 ; 100 ; 150 \mathrm{mg} / \mathrm{l} ; \mathrm{Cr}-2.5 ; 5 ; 10 \mathrm{mg} / \mathrm{l}$. There was also a test case. During the experiment, the diameter of the mycelium of fungi and their growth rate were measured. The peculiarities of the response of fungi to stress conditions were assessed by the content of malondialdehyde (MDA), which is a product of lipid oxidation. It should be noted that a number of studies confirm the dependence of the MDA concentration in the fungal mycelium on the HM content in the substrate; therefore, this indicator can serve as a biomarker of stress conditions in which endophytes find themselves $[4,12]$. The content of MDA in mushrooms was estimated by the degree of accumulation of the product of its reaction with thiobarbituric acid (TBA), determining the optical density of the solution on a spectrophotometer at a wavelength of $532 \mathrm{~nm}$. For this, $2 \mathrm{ml}$ of distilled water and $3 \mathrm{ml}$ of $10 \%$ TCA were added to a test tube with mushroom biomass. A $2 \mathrm{ml}$ sample was taken from the resulting homogenate and $0.5 \%$ TBA was added.

\section{Analysis of the effect of different concentrations of copper and chromium on the growth of Fusarium equiseti and Cylindrocarpon magnusianum}

The results of measuring the mycelium diameter and the growth rate of Fusarium equiseti are shown in Figures 1-2, Cylindrocarpon magnusianum - in Figures 3-4.

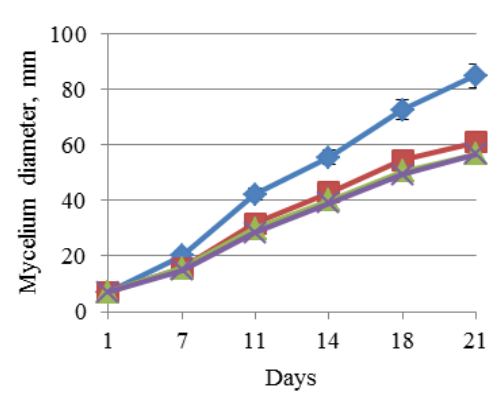

A

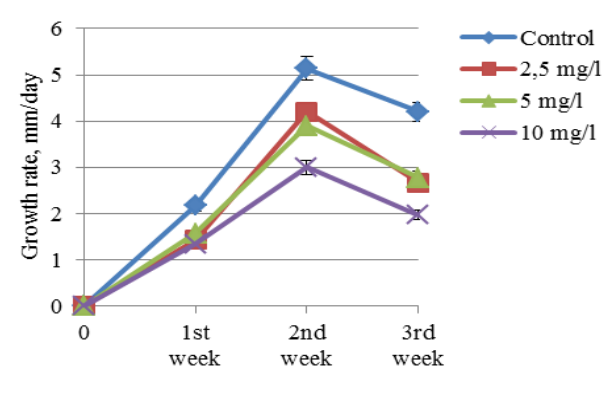

B

Fig. 1. Size dynamics (A) and growth rate (B) of Fusarium equiseti on substrates with different chromium concentrations 


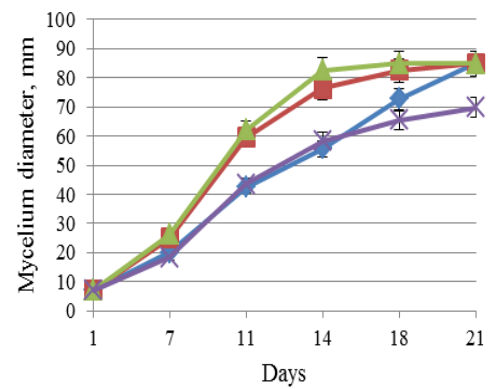

A

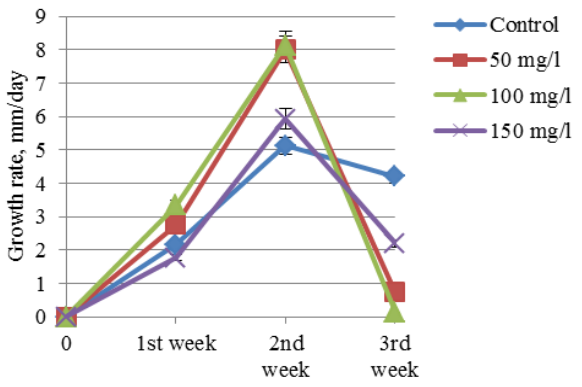

B

Fig. 2. Size dynamics (A) and growth rate (B) of Fusarium equiseti on substrates with different copper concentrations

The experimental results showed that the chromium content in the medium influenced the growth of $\mathrm{F}$. equiseti. The diameter and growth rate of the fungal mycelium at all metal concentrations in the substrate were significantly lower than in the control. At the same time, there were no significant differences between the variants themselves in the size of the diameter.

F. equiseti showed great resistance to copper. At concentrations of 50 and $100 \mathrm{mg} / \mathrm{l}$, the diameter of the fungal mycelium at the beginning of the experiment exceeded the control values. The growth rate of mycelium also at the beginning of the experiment was significantly higher than the control at concentrations of 50 and $100 \mathrm{mg} / \mathrm{l}$.

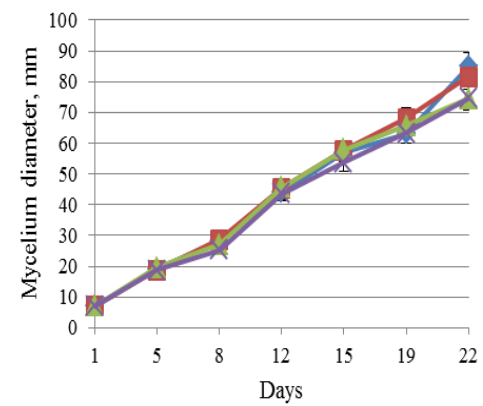

A

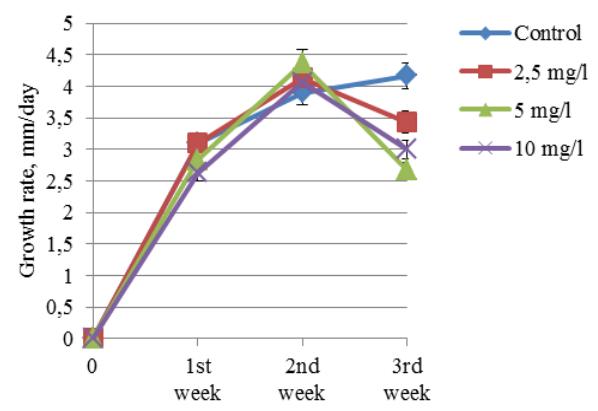

B

Fig. 3. Size dynamics (A) and growth rate (B) of Cylindrocarpon magnusianum on substrates with different chromium concentrations 


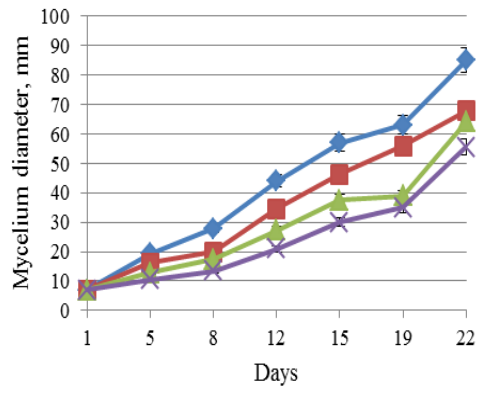

A

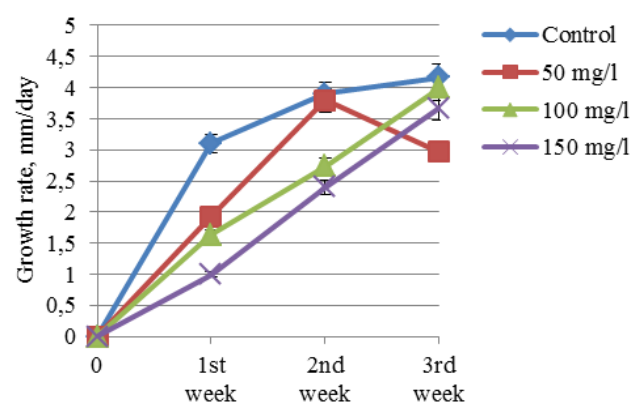

B

Fig. 4. Size dynamics (A) and growth rate (B) of Cylindrocarpon magnusianum on substrates with different copper concentrations

The chromium content in the medium had no inhibitory effect on C. magnusianum. The diameter of the fungus mycelium at all metal concentrations in the medium did not differ significantly from the control. The growth rate of the fungal mycelium did not differ from the control in all variants of the experiment.

Copper, on the other hand, had an inhibitory effect on the growth of C. magnusianum. With an increase in the concentration of copper in the substrate, a decrease in the diameter of the mycelium was observed. The growth rate of mycelium at the beginning of the experiment was significantly lower than in the control.

The results of determining the MDA content in the mycelium of fungi are presented in Table 1.

Table 1. Malondialdehyde content in the mycelium of Fusarium equiseti and Cylindrocarpon magnusianum, $\mu \mathrm{mol} / 1 \mathrm{~g}$ wet weight

\begin{tabular}{|c|c|c|}
\hline $\begin{array}{l}\text { HM salt content in } \\
\text { the medium }\end{array}$ & $\begin{array}{l}\text { MDA content in Cylindrocarpon } \\
\text { magnusianum }\end{array}$ & $\begin{array}{c}\text { MDA content in Fusarium } \\
\text { equiseti }\end{array}$ \\
\hline $\begin{array}{c}\text { Without HM } \\
\text { (control) }\end{array}$ & $2.034 \pm 0.047^{1}$ & $1.290 \pm 0.071$ \\
\hline Cr $2.5 \mathrm{mg} / 1$ & $6.092 \pm 0.585 \uparrow^{2}$ & $1.743 \pm 0.071 \uparrow$ \\
\hline Cr 5mg/l & $7.276 \pm 1.115 \uparrow$ & $1.760 \pm 0.070 \uparrow$ \\
\hline $\mathrm{Cr} 10 \mathrm{mg} / \mathrm{l}$ & $3.881 \pm 0.054 \uparrow$ & $1.142 \pm 0.014$ \\
\hline $\mathrm{Cu} 50 \mathrm{mg} / \mathrm{l}$ & $2.031 \pm 0.021$ & $2.227 \pm 0.230$ \\
\hline $\mathrm{Cu} 100 \mathrm{mg} / \mathrm{l}$ & $3.571 \pm 0.431 \uparrow$ & $6.368 \pm 0.775 \uparrow$ \\
\hline $\mathrm{Cu} 150 \mathrm{mg} / \mathrm{l}$ & $4.117 \pm 0.291 \uparrow$ & $8.076 \pm 0.311 \uparrow$ \\
\hline
\end{tabular}

The content of MDA in the mycelium of F. equiseti and C. magnusianum grown on a substrate containing chromium in different concentrations exceeded the control values. Only at the highest concentration $(10 \mathrm{mg} / \mathrm{l})$, the MDA content in the mycelium did not differ significantly from the control. At the same time, the growth rate of $\mathrm{F}$. equiseti mycelium at this concentration during the entire experiment was the lowest in comparison with other experimental variants, although there was no significant difference with the control. In the mycelium of C. magnusianum at the highest chromium concentration, the MDA content was significantly lower than in other variants, but remained higher than in the control. 
From here, we can conclude that the chromium content in the substrate caused a stress reaction in $\mathrm{F}$. equiseti, but the organism, having overcome the adaptation period, resumed growth processes.

In the experiment with copper, the MDA content in the mycelium of F. equiseti and $\mathrm{C}$. magnusianum at the lowest metal concentration in the substrate $(50 \mathrm{mg} / \mathrm{l})$ did not differ significantly from the control. As the copper concentration in the substrate increased, the MDA content in the fungal mycelium increased and reached its maximum values at a concentration of $150 \mathrm{mg} / \mathrm{l}$. Since the growth of mycelium continued at a given copper concentration in the substrate, it can be concluded that MDA synthesis played a role in the system of adaptive responses of the fungus.

\section{Conclusions}

1. Endophytic fungi are promising objects for study as agents for increasing plant resistance. They have a wide distribution area, diverse morphology and are able to adapt to stressful environmental conditions [9]. At the same time, the habitat of micromycetes plays an important role in their resistance to pollutants. Fungal cultures isolated from contaminated soils have wider tolerance limits to the action of the pollutant $[10,11,12]$.

2. Fusarium equiseti and Cylindrocarpon magnusianum showed high metal resistance to chromium and copper. Herewith C. magnusianum showed great resistance to chromium, while $\mathrm{F}$. equiseti - to copper.

3. The results of the analysis of the MDA content in the mycelium of fungi suggest that the synthesis of MDA and an increase in its concentration in the mycelium is a reaction to an increase in the concentration of HM in the substrate. Thus, F. equiseti and C. magnusianum exhibit an adaptive response to the content of copper and chromium in the substrate and can be used in the development of the technology of increasing plant resistance to heavy metal salts.

\section{Acknowledgements}

The research was carried out with the support of the RFBR grant "Postgraduates" No. 19316-90003.

\section{References}

1. S.V. Zheleznyakov, V.K. Lebedeva, R.V. Smetanin, L.M. Yakobi, Mycology and Phytopathology, 3 (2020)

2. N.A. Islamova, I.L. Buharina, A.A. Kamasheva, R.G. Latypova, M.A. Lebedeva, A.S. Pashkova, Modern problems of science and education, 3 (2015)

3. E.N. Vasil'eva, G.A. Akhtemova, V.A. Zhukov, I.A. Tikhonovich, Environmental Genetics, 17 (2019)

4. I.L. Bukharina, Modern problems of the development of technology, economy and society (2016)

5. L. Yan, J. Zhu, X. Zhao, J. Shi, C. Jiang, D. Shao, Applied Microbiology and Biotechnology, 103 (2019)

6. R.J. Rodriguez, R.S. Redman, J.M. Henson, Mitigation and Adaptation Strategies for Global Change, 9 (2004) 
7. A. Ali, S. Bilal, A. L. Khan, F. Mabood, A. Al-Harrasi, I. Lee, Journal of Plant Interactions, 14 (2019)

8. V.R. Murphy, F.M. Doohan, T.R. Hodkinson, Journal of Agricultural Science, 152 (2014)

9. V. Kumar, S.K. Dwivedi, Chemosphere, 237 (2019)

10. J. Rydlova, M. Vosatka, Folia Geobotanica, 155 (2003)

11. A.M. Domka, P. Rozpadek, K. Turnau, Frontiers in Microbiology, 10 (2019)

12. L. Hou, J. Yu, L. Zhao and X. He, Frontiers in Microbiology, 10 (2020)

13. J.G. Maciá-Vicente, H.-B. Jansson, N.J. Talbot, L.V. Lopez-Llorca, New Phytologist, 182 (2009)

14. H. Ramdial, R.K. Latchoo, F.N. Hosein, S.N. Rampersad, Phytopathology, 107 (2017)

15. M.H. Wheeler, R.D. Stipanovic, L.S. Puckhaber, Mycological Research, 103 (1999)

16. M.V. Sogonov, L.L. Velikanov, Mycology and Phytopathology, 38 (2004) 